\title{
A gestão ambiental e a análise do uso racional e ecologicamente correto dos recursos naturais e seus processos no centro de tecnologia da Universidade Federal do Ceará
}

\author{
Ivan de Oliveira', Francisco Ernane Abreu Gadelha² \\ 'Professor Universitário, Instituto de Ciências do Mar/LABOMAR, Universidade Federal do Ceará, Fortaleza, Brasil \\ ¿Universidade Federal do Ceará, Fortaleza, Brasil
}

\begin{abstract}
Resumo
Esta pesquisa trata da gestão ambiental. Aborda o planejamento ambiental e o uso racional dos recursos naturais. Realiza um estudo de caso no Centro de Tecnologia da UFC (CT), sobre a forma de consumo da água, energia elétrica, papel e o destino dos resíduos gerados nos processos. $\mathrm{O}$ percurso metodológico deste trabalho se vale dos seguintes tipos de pesquisa: bibliográfica, de campo e exploratória. $\mathrm{Na}$ pesquisa de campo aplicou-se um questionário composto por perguntas estruturadas e semiestruturadas e entrevista aos principais gestores. Utilizou-se ainda da pesquisa exploratória na definição de objetivos e na busca de mais informações sobre o tema. Os resultados supriram as hipóteses, e mostraram que o CT tem características socioambientais, entretanto, não tem um programa de gestão ambiental estruturado e comete desperdícios. A pesquisa indicou ainda que o CT deve participar da Agenda Ambiental da Administração Pública (A3P), instrumento para a promoção de melhoria sistemática de seus processos.
\end{abstract}

Palavras-chave: Gestão Ambiental; Recursos Naturais; Água e Energia Elétrica.

\begin{abstract}
This research deals with environmental management and the treaties related to the topic. Addresses the environmental planning and the rational use of natural resources. Performs a case study in the technology Center of UFC (CT), about the pattern of consumption of water, electrical energy, paper and the destination of waste generated in the process. The methodological approach of this work uses the following types of research: literature, field and exploratory. In the field research was applied to a questionnaire; supplement it with interviews of main managers. The exploratory research was also used in defining goals and finding more information about the subject. The results have supplied the hypotheses, and showed that $\mathrm{CT}$ has social and environmental characteristics, however, has not an environmental management program structured and makes wastes. The search also indicated that CT should participate in the Environmental Agenda for Public Administration (A3P), tool to promote systematic improvement of its processes.
\end{abstract}

Keywords: Environmental Management, Natural Resources, Water and Electrical Energy. 


\section{INTRODUÇÃO}

O tema "gestão ambiental" ganhou espaço nos meios de comunicação que vêm dando destaque especial às iniciativas voltadas para o desenvolvimento sustentável. Este fato tem provocado a mobilização da sociedade civil para o tema, e como consequência disso, há o surgimento de diversas organizações não-governamentais (ONGs) com a missão de proteger o meio ambiente. Por outro lado, incentivados por organismos internacionais, os governos têm se manifestado em fóruns, a exemplo, as conferências de Estocolmo, na Suécia em 1972; habitar, em Vancouver no Canadá em 1976; e no Brasil a Rio 92, ocorrida no Rio de Janeiro, promovida pela Organização das Nações Unidas (ONU) que contou com a presença de 175 países. (www.onu.org.br.)

Como resultado da Rio 92, foi aprovada a convenção do clima, pela qual os países signatários, inclusive o Brasil, reduziriam primeiramente as emissões de gazes poluentes, até o ano 2000, aos mesmos níveis de emissão vigentes em 1990; e em 2010 para um nível 10\% inferior ao de 1990. O Protocolo de Kyoto, um instrumento internacional, ratificado em 15 de março de 1998, que definiu metas de reduzir as emissões de gases poluentes responsáveis pelo efeito estufa e o aquecimento global. O Protocolo de Kyoto entrou oficialmente em vigor no dia 16 de fevereiro de 2005, após ter sido discutido e negociado em 1997, na cidade de Kyoto (Japão). Conferência de Copenhague (COP 15) em dezembro de 2009, instrumento pelo qual se esperava a definição de regras para o segundo período do compromisso do Protocolo de Kyoto, não atingiu esse objetivo. (www.mma.gov.br/clima/protocolo-de-Quioto).

Nesse contexto de preocupação mundial com o meio ambiente, as universidades podem somar esforços e aliarem-se a outros setores da sociedade para combater as práticas ambientalmente incorretas, principalmente contribuindo como partícipe, ou como autoras de políticas públicas que visem diminuir a poluição a partir da gestão ambiental, fomentando as práticas do desenvolvimento sustentável. Para a Universidade Federal do Ceará (UFC), fundamentado no Decreto 5.940/2006, este deve ser um caminho natural, dado seu compromisso de ser exemplo para a formação de cidadãos mais responsáveis e preocupados com o universo em que vivem.

A estrutura atingida pelo estudo, o Centro de Tecnologia (CT) da UFC, é composta por: 3.450 estudantes, 188 professores, 69 servidores, distribuídos em 9 departamentos, 9 cursos de graduação, 11 cursos de mestrado, 4 cursos de doutorado, e 56 laboratórios.

Analisar o comportamento socioambiental de uma parte importante de uma instituição pública do ensino superior como o Centro de Tecnologia, foi especialmente uma tarefa desafiadora e que possibilitou a investigação, a reflexão pessoal, a criticidade, o envolvimento e a conscientização de valores necessários para o cumprimento do exercício da cidadania.

\section{LEGISLAÇÕES AMBIENTAIS BRASILEIRAS}

A legislação ambiental é um conjunto de leis, normas, regras e padrões com a finalidade de disciplinar a atividade humana, para torná-la compatível com a proteção do meio ambiente. A preocupação e/ou conscientização por parte do poder público, em países desenvolvidos e em alguns em desenvolvimento, se dá a partir da década de sessenta. No Brasil, as leis voltadas para a conservação ambiental começaram a ser votadas a partir de 1981, com a lei que criou a Política Nacional do Meio Ambiente (lei ${ }^{\circ}$ 6.938, de 31 de agosto de 1981).

A legislação ambiental é um dos utensílios para implantar atividades causadoras de impactos ambientais, e alta degradação e a poluição do meio ambiente levaram o poder público a pensar em formas para controlar os impactos causados por tais atividades. O crescimento da conscientização ambiental do público, em países desenvolvidos e alguns em desenvolvimento, se deram a partir da década de sessenta. (LIMA, 2005).

Todavia, a Constituição é a lei maior de um país. Em síntese, é o conjunto de normas que organizam os elementos constitutivos do Estado que compreende o território, a população e o governo. Para Barros e Monticelli (1998, p. 509) "a Constituição Federal é o fundamento de toda a legislação e dela deriva toda a ordem jurídica".

Assim, de acordo com Almeida, Mello e Cavalcanti (2002), a lei n ${ }^{\circ} 6.938 / 81$ é considerada por alguns autores como um "divisor de águas" no que se refere a legislação ambiental. A principal diferença é que a partir dela as questões ambientais tomam um novo norteamento, pois passam a existir 
punições aos transgressores, prevendo penalidades e multas. A conservação e o uso sustentável dos recursos naturais como o solo, a água, as plantas, os animais e os minerais são de grande importância para a manutenção da vida na terra. Os recursos naturais de uma determinada área são seu capital básico e o mau uso dos mesmos constitui uma perda econômica. Do ponto de vista ecológico, a conservação inclui também a manutenção das reservas naturais e da fauna autóctone, enquanto do ponto de vista cultural inclui a preservação dos lugares históricos. Assim cabe aos geógrafos e também a todas as pessoas, zelar pela manutenção, recuperação e preservação dos recursos naturais, utilizando-os de forma sustentável.

Em grande parte do nosso país prevalece a apresentação do EIA/RIMA para o licenciamento de empreendimentos, no entanto, há novas tendências para a legislação ambiental. Conforme Barros e Monticelli (1998, p. 512):

Em São Paulo, algumas modificações estão ocorrendo, no sentido de tornar mais eficiente a atuação do poder público, das empresas de consultoria e dos empreendedores [...] estão sendo realizadas audiências públicas, nas quais a apresentação de relatórios simplificados, previamente ao EIA/ RIMA, evitam custos ao empreendedor e não criam expectativas sobre um empreendimento que pode ser vetado pelo poder público, devido aos impactos ambientais.

De acordo com os autores, percebe-se a necessidade tanto em órgão público como nas câmaras e conselhos e até os próprios EIAs/RIMAs que exigem equipes multidisciplinares para elaborá-los. O problema é que essa multidisciplinaridade é empregada apenas na elaboração do projeto, mas não nas fases posteriores como a licença de instalação e o acompanhamento da operação.

Na visão de Silva (1999), a lei de crimes ambientais ( $\left.n^{\circ} 9.605 / 98\right)$, recentemente aprovada pelo Congresso Nacional, representa para a Nação Brasileira e, especialmente para o meio ambiente, um enorme avanço, pois apresenta perfeita sintonia com os anseios da população, em função do despertar da sociedade para o exercício da cidadania e os valores que o meio ambiente representa para a sadia qualidade de vida. A poluição, as substâncias tóxicas, o lançamento de resíduos sólidos, líquidos ou gasosos, detritos, óleos ou substâncias oleosas, também receberam tratamento exemplar na lei de crimes ambientais, ou seja, aquele que causar poluição de qualquer natureza em níveis tais que resultem ou possam resultar em danos à saúde humana, ou que provoquem a mortandade de animais ou a destruição da flora, serão punidos com a pena de reclusão de 1 a 5 anos. Ela criminaliza também condutas consideradas reprováveis como a pichação de bens públicos e a realização de grandes obras sem o estudo de impacto ambiental.

No âmbito da administração pública o Ministério do Meio Ambiente institui a Portaria de $\mathrm{n}^{\circ}$ 221, de 14 de setembro de 2004, estabelecendo a Agenda da Administração Pública, a A3P. Esta tem por objetivo estimular os gestores públicos a incorporar princípios e critérios de gestão ambiental em suas atividades rotineiras, levando à economia de recursos naturais e à redução de gastos institucionais por meio do uso racional dos bens públicos e da gestão adequada dos resíduos.

\section{I Agenda Ambiental da Administração Pública (A3P)}

As questões geradas pela administração pública nas três esferas (federal, estadual e municipal) revelam excessivo consumo de recursos naturais, razão pela qual o governo federal precisa assumir papel estratégico na indução de novos referenciais de produção e consumo, orientados para a sustentabilidade. Cabe também aos órgãos que compõem a administração pública dar o primeiro passo na direção da redução do consumo de recursos naturais, diminuindo impactos ambientais em suas atividades, incentivando combate ao desperdício e programas de práticas de reaproveitamento e reciclagem de materiais (MMA/COMISSÃO GESTORA DA A3P, 2005).

Desta maneira, a A3P é um programa de caráter voluntário que se propõe a inserir critérios ambientais nas áreas de governo, visando minimizar ou eliminar os impactos ao meio ambiente, provocados por atividades administrativas ou operacionais. Esta agenda é uma resposta a uma das recomendações contidas na Agenda 21 resultado ainda da Eco Rio/92. Em 1999 o Ministério do Meio Ambiente criou sua primeira Comissão Permanente, e a partir dali o programa passou a ser incluído nas ações de competência da Secretaria de Políticas para o Desenvolvimento Sustentável, que estabelece a ligação com as ações que buscam a ecoeficiência governamental. De lá até os nossos dias, o Ministério do Meio Ambiente tem sido um forte incentivador de sua implantação em todos os níveis governamentais (MMA..., 2005).

Todavia, a A3P é um programa que visa programar a gestão socioambiental sustentável dentro 
das atividades administrativas e operacionais do governo, e tem como objetivo primordial minimizar os impactos ao meio ambiente, provocados por atividades administrativas ou operacionais. O programa estabelece critérios ambientais nos órgãos governamentais, desde os pequenos cuidados dentro das rotinas de trabalho, como o uso racional dos bens duráveis e do material de consumo, na economia responsável de insumos como água e energia, passando pela gestão adequada dos resíduos gerados e também com relação aos investimentos, custeio e contratação de serviços, ações que visam a estabelecer além da diminuição dos referidos impactos ambientais, uma melhoria na qualidade de vida no próprio ambiente de trabalho.

A A3P tem como diretriz principal a sensibilização não só dos gestores, mas de todos os colaboradores do serviço público, em todas as suas esferas, para as questões socioambientais, buscando o equilíbrio responsável entre o homem e o ambiente. É importante ressaltar que o engajamento ao programa é voluntário, resta o desafio individual e coletivo, dentro do conceito deste novo modelo de gestão pública, ambientalmente responsável, repensar a nossa postura pessoal e profissional na construção dessa nova cultura institucional. O mais importante é compreender que o grande desafio está na mudança de nossa consciência, assim passaremos de meros expectadores a atores principais na defesa do equilíbrio ambiental e da vida na terra.

O programa Agenda Ambiental na Administração Pública, ou A3P, caracteriza-se como uma ação voluntária a fim de inserir a adoção de um modelo de gestão pública que corrija e diminua impactos negativos gerados durante a jornada de trabalho. O meio de conseguir isso é o uso eficiente dos recursos naturais, materiais, financeiros e humanos. Este programa vem sendo coordenado pela Secretaria de Políticas para o Desenvolvimento Sustentável e tem levado sua experiência aos órgãos governamentais, nos três níveis de governo, mediante solicitação dos interessados.

Em relação ao objetivo da $\mathrm{A} 3 \mathrm{P}$, muitas empresas e instituições governamentais ou não-governamentais têm estabelecido agendas ambientais e Agendas 21. Nesse processo, pensar sobre o meio ambiente e suas interfaces equivale a desenvolver um plano de ações que contemplem as possibilidades de execução de cada instituição. Na avaliação das implicações ambientais, não se pode esquecer que o homem é o integrante diferencial do meio ambiente - que, na prática é um todo formado por partes igualmente complexas, geralmente frágeis e passivas (MMA..., 2005).

A A3P amplamente soma-se a toda instituição que já se moveu no sentido de que é preciso repensar sua posição diante das ações que vem sendo realizadas antecipadamente pela iniciativa privada. Antes de desencadear uma ação dessa natureza, é preciso que seja estabelecido um processo metodológico básico, contínuo, capaz de orientar as etapas, desde a sua concepção até a implementação das ações e sua manutenção. O Ministério do Meio Ambiente (MMA) vem construindo a sua Agenda Ambiental, visando a melhoria das relações com o ambiente, em suas atividades diárias, e das relações interpessoais entre os servidores.

Ocorre que o Programa Nacional de Educação Ambiental, elaborado e aprovado pelo MMA em 1999, previa a construção de agendas ambientais por um processo participativo que possibilitasse o aprendizado das questões ambientais. Aqui entra a reflexão de cada ser humano para criar uma fase transitória entre o velho e o novo paradigma. Com o resgate de valores esquecidos e a adoção de novos, seremos capazes de mudar comportamentos, hábitos e atitudes, visando a vida saudável da geração presente e o não comprometimento da boa qualidade para as gerações futuras.

Em agosto de 1999, o MMA criou a Comissão Permanente, composta por representantes de suas unidades, incluindo o Instituto Brasileiro do Meio Ambiente (IBAMA), além de um representante do Centro de Desenvolvimento Sustentável da Universidade de Brasília. Essa comissão, juntamente com os demais servidores voluntários, identificou problemas e propôs ações básicas para solucioná-los, de um modo contínuo, que sempre se renova. Da mesma forma, cada representante de unidade ficou responsável por procedimentos que considerassem peculiares à ambiência de suas unidades, num processo de multiplicação e incorporação de atitudes próprias e saudáveis.

A partir de setembro de 2000, o Programa A3P passou a ser incluído nas ações de competência da Secretaria de Políticas para o Desenvolvimento Sustentável, que estabelece a ligação com as ações administrativas, as quais buscam a ecoeficiência governamental.

No período de 1999/2000, 16 reuniões visaram distribuir tarefas, realizar diagnósticos, colher sugestões junto aos servidores, caracterizar e quantificar os resíduos gerados e identificar materiais alternativos; objetivaram ainda avaliar a inclusão de critérios ambientais nos processos licitatórios, dando preferência aos parceiros com os mesmos princípios ambientais. Mas, estabelecer novas formas 
de sensibilização e motivação dos servidores, elaboração de materiais didático-pedagógicos, informativos, e a promoção de eventos para uma troca descontraída de informações.

A implantação da A3P requer planejamento, além do desenvolvimento de ações educativas e de treinamento. A ação só será efetiva com o comprometimento da instituição em minimizar ou eliminar impactos ambientais, diretos ou indiretos, decorrentes de suas atividades. Esse planejamento deverá apresentar procedimentos para atingir os objetivos estabelecidos e ter em destaque as ações de educação e capacitação.

\subsection{Gestão Ambiental nas Instituições Federais de Ensino Superior Brasileiras}

As universidades brasileiras ainda encontram inúmeros obstáculos para incorporar a dimensão ambiental à formação de recursos humanos devido a vários fatores, como: abordagem da questão ambiental de forma setorial e multidisciplinar, estudos de caráter técnico em detrimento dos aspectos epistemológicos e metodológicos. (RODRIGUES, OLIVEIRA E PILATTI (2007))

Furiam e Gunther (2006) afirmam que os resíduos sólidos gerados em ambientes universitários englobam, além daqueles classificados com resíduos sólidos urbanos, alguns resíduos classificados como industriais e como resíduos de serviços de saúde. Existe ainda, conforme os mesmos autores, as atividades de educação ambiental que são importantes para orientar a segregação, a coleta, o tratamento e a destinação final desses resíduos sólidos gerados nesses ambientes, uma vez que requerem um tratamento especial.

Nolasco, Tavares e Bendassolli (2006), afirmam que as experiências no sentido do sistema de gestão ambiental no Brasil vêm sendo realizadas na última década, porém em casos de iniciativas separadas, principalmente em algumas das maiores e mais antigas universidades estaduais e federais. A primeira IES a implantar a ISO 14001 foi a Universidade do Vale do Rio dos Sinos, no Rio Grande do Sul, por intermédio do projeto Verde Campus, que visa à preservação, à melhoria e à recuperação da qualidade ambiental e socioeconômica (VERDE CAMPUS, 1997).

Ribeiro et al. (2005) afirmam que a Universidade Federal de Santa Catarina está na tentativa da implantação do sistema de gestão ambiental, estando ligada diretamente com a diretoria e reitoria da universidade, tendo como política ambiental utilizar o ensino como um uma busca contínua para melhorar a relação homem e meio ambiente. A Universidade Regional de Blumenau criou o comitê de implantação do sistema de gestão ambiental em 1998, constituído por representantes de toda a comunidade universitária, objetivando identificar com clareza os seus problemas ambientais, a fim de estabelecer um plano de melhoria contínua na atenuação destes.

Ainda conforme os mesmos autores do supracitados, a Universidade Federal do Rio Grande do Sul vem implantando o sistema de gestão ambiental, realizando inicialmente o diagnóstico sobre os resíduos gerados e suas diferentes destinações, nas unidades da universidade. O curso de Engenharia de Materiais programou o sistema de gerenciamento de Resíduos Sólidos Urbanos em 2004, com ações de diminuição do consumo de água e energia. A Universidade de Horizontina (RS) desenvolveu através dos estudos de Tauchen (2007) um modelo para a implantação de gestão ambiental para as instituições de ensino proposto através da Norma ISO 14001.

Os problemas existentes para as IES implantarem um sistema de gestão ambiental são: a falta de informação da sociedade sobre práticas sustentáveis; a não valorização do meio ambiente por diversos colaboradores da organização; a não percepção da universidade como uma fonte potencial de poluição (RIBEIRO et al., 2005).

Dessa forma, fica claro que as instituições de ensino superior são pouco exploradas e restritas em relação ao seu gerenciamento ambiental, porém mostram a sua preocupação com o desenvolvimento sustentável, tanto no que diz respeito ao ensino dos alunos, quanto às práticas ambientais ao ambiente.

As IES brasileiras estão preocupadas com o gerenciamento dos resíduos, desenvolvendo programas externos de reciclagem, controles no consumo de água, energia e nos descartes dos resíduos líquidos gerados nos laboratórios, principalmente nas áreas químicas. Outras IES apresentam certificações da Norma ISO 14001 ou ainda estão em busca destas, pois são observados grandes problemas para a implantação da Norma ISO 14001, devido à falta da visão sistêmica nas IES, trazendo dificuldades com a direção, que por sua vez ocasionam problemas com a manutenção, não tendo assim uma continuidade da iniciativa desse sistema de gerenciamento ambiental. 


\section{GESTÃO AMBIENTAL NO CENTRO DE TECNOLOGIA DA UNIVERSIDADE FEDERAL DO CEARÁ}

A abordagem desse trabalho no CT, teve como objetivo pesquisar as formas de consumo de água, energia, e papel, além de investigar possíveis desperdícios ou mau uso desses insumos produzidos a partir de recursos naturais, relatando ainda a distribuição quanto à aplicação destes por unidade pesquisada, proporcionalmente nos processos de ensino, pesquisa, extensão. Além disso, consultamos qual a opinião dos pesquisados sobre a implantação da Agenda Ambiental da Administração pública no CT.

\section{I CONSUMO DE ENERGIA ELÉTRICA.}

O processo de distribuição de energia elétrica dentro do campus ocorre da seguinte forma: a COELCE fornece com medição única a energia na tensão de 13.800 Volts para o campus como um todo. Existem distribuídas no campus várias unidade de transformação que rebaixam essa tensão para 380 e 220 volts e que é distribuída para as unidades consumidoras (prédios) e a rede de iluminação pública local. Portanto, não existe um medidor de consumo de energia em cada unidade.

O fato de não haver medição por unidade consumidora, ao contrário da água que tem em cada prédio o seu hidrômento, impossibilita o acompanhamento mensal do consumo por unidade, não tendo assim como mensurar a eficácia de eventuais campanhas de combate ao desperdício de energia, portanto sugerimos a partir desse trabalho que seja instalado em cada prédio do CT um wattímetro (medidor de energia) instrumento importantíssimo que permitirá fazer uma leitura paralela de consumo individualizado para uso interno na gestão do consumo.

Portanto, esse trabalho, visto que ainda não há as condições sugeridas no segundo parágrafo acima, decidimos fazer uma análise sobre forma de consumo e eventuais desperdícios baseado em instrumento de pesquisa, um questionário misto de questões fechadas e abertas. $\mathrm{O}$ centro em estudo conta com 10 unidades de transformação que alimentam 22 unidades consumidoras.

\subsection{CONSUMO DE ÀGUA.}

Para o melhor entendimento de como funciona o consumo, descreveremos o sistema de distribuição de água no CT. Essa questão nos remete ao antigo modelo de cadastramento da UFC com a CAGECE. Pelas normas da companhia, existem as economias, que são entendidas como um conjunto de prédios ou pavimentos onde o consumo é apurado por uma única medição. Por outro lado, a companhia aplica intervalos de preço por faixa de consumo, portanto, como havia várias unidades consumidoras registrando em um só hidrômetro, a conta sempre era cobrada com base em tarifa que ultrapassava todos os intervalos de consumo, gerando assim, uma tarifa muito mais cara.

Existiam 7 (sete) hidrômetros (economias) no CT que distribuiam água para 22 unidades consumidoras, fora o consumo dos jardins. Os problemas decorrentes desse modelo geravam não só uma conta mais cara por consequência da questão tarifária, mas também desperdícios resultantes das constantes quebras de tubulação, que chegava em alguns casos percorrer $60 \mathrm{~m}$ de distância do hidrômetro à unidade de consumo.

Para exemplificar, um hidrômetro instalado no bloco 709 distribuía água para as caixas d'água dos blocos 709 e 708. Por gravidade, essas águas abasteciam os blocos 706 e 711, ou seja, a conta dos quatro blocos abastecidos era registrada em um só hidrômetro.

Com o recadastramento, o CT passou de 7 para 22 hidrômetros. Com isso o fornecimento ficou mais próximo da unidade consumidora, diminuindo a distância percorrida pelos tubos, o que implica em menos risco de desperdícios de água por quebra de tubulação.

\subsection{Consumo de PAPel}

Segundo dados do Worldwatch Institute, o alto consumo de papel e seus métodos de produção insustentáveis transmitem a relação das atividades humanas mais prejudiciais ao planeta. O consumo mundial de papel cresceu mais de seis vezes desde a metade do século XX, podendo chegar a mais de $300 \mathrm{~kg}$ per-capita ao ano em alguns países.

O papel é a matéria-prima fundamental para a execução das atividades educacionais e administrativas, por isso, o consumo abusivo desse recurso acarreta problemas econômicos, educacionais e ambientais, tais como: esgotamento de recursos naturais, poluição do solo, ar e comprometimento da qualidade das atividades que dependem desse recurso (BRAGA et al., 2002). 
Neste contexto, o Centro de Tecnologia, por se tratar de um centro de excelência acadêmica capaz de graduar e pós-graduar profissionais na área de Engenharia Ambiental, tem por o dever de ser exemplo para a sociedade. No intuito de contribuir, esse trabalho pretende a partir das informações sobre o consumo de papel no CT, estimular o uso racional.

\subsection{Destino dos RESíduOS Sólidos No CENTRO DE TECNOLOGIA}

Os resíduos oriundos dos processos realizados no CT são bastante diversificados em consequência do número de laboratórios e a especificidade das atividades. Segundo informações dos pesquisados, os resíduos comuns, Classe D (papéis, metais, madeiras, plásticos, entulhos de construção) são colocados em contêiner da coleta de rotina da UFC.

Dos contaminastes, Classe B - resíduos que apresentam risco potencial à saúde pública e ao meio ambiente devido às suas características químicas, parte é colocada em depósitos especiais fornecidos pela atual empresa contratada para coleta, entretanto, ainda há tipos muito específicos que estão sendo armazenados em depósitos especiais adequados, para posterior destruição dentro das normas de segurança.

Para melhor esclarecimento sobre os temas, realizamos uma análise sobre forma de consumo e eventuais desperdícios de água, energia elétrica e papel, bem como o destino dos resíduos e a participação do CT na Agenda ambiental da Administração Pública (A3P).

\section{METODOLOGIA}

\section{I População Pesquisada}

A estrutura atingida pela pesquisa de estudo de caso, o Centro de Tecnologia (CT) da Universidade Federal do Ceará, é composta por 3.450 estudantes, 188 professores, 69 servidores, distribuídos em 9 departamentos, 9 cursos de graduação, 11 cursos de mestrado, 4 cursos de doutorado, 56 laboratórios. O público pesquisado será composto com base seguinte critério: 1. Diretor do Centro de Tecnologia; 2. Chefes dos Departamentos do CT; 3. Chefes dos laboratórios do CT; 4. Presidente dos Centros acadêmicos (representação estudantil); 5. Servidores técnicos administrativos numa proporção de $10 \%$ do total. Com base no critério de maior tempo de serviço.

A descrição da amostra pode ser feita da seguinte forma: 42 professores; 10 técnicos-administrativos e 06 estudantes (presidentes dos centros acadêmicos).

\subsection{INSTRUMENTOS E PROCEDIMENTOS DA COLETA DE DADOS}

Para este estudo aplicamos um questionário composto por perguntas estruturadas e semiestruturadas, e entrevistas aos principais gestores. Para Bastos (2003, p. 40) "Uma das vantagens do questionário, dentre outras, é garantir certa uniformidade das respostas devido ao caráter padronizado das perguntas."

\section{APRESENTAÇÃO DOS DADOS E ANÁLISE DOS RESULTADOS}

A análise será feita, mostrando o resultado da tabulação das respostas às perguntas feitas no questionário. Para tanto usamos quadros e outros aplicativos para apresentar de forma mais clara os resultados.

1) A energia elétrica é aplicada em quais atividades nessa unidade?

Quadro 3 - Modelo explicativo da questão 1.

\begin{tabular}{|l|l|l|}
\hline \multicolumn{1}{|c|}{ LEGENDA } & \multicolumn{1}{c|}{ ATIVIDADES DE USO } & \multicolumn{1}{c|}{ EQUIPAMENTOS QUE USAM ÁGUA } \\
\hline $\mathrm{P}, \mathrm{E}, \mathrm{EX}$ & Humano, Pesquisa e extensão. & Laboratórios, salas de aula, eventos. \\
\hline $\mathrm{P}, \mathrm{E}$ & Laboratório e salas de aula & Eletroeletrônicos e salas de aula \\
\hline $\mathrm{P}$ & Exclusivamente pesquisa & Exclusivamente eletroeletrônicos \\
\hline $\mathrm{EX}$ & Projetos e eventos & Anfiteatro, ETEs. \\
\hline
\end{tabular}

Fonte: Elaboração própria. 
O resultado mostra que:

- O percentual de $52 \%$ do uso de energia no CT se concentra distribuído em atividades de pesquisa, ensino e extensão (P, E, EX);

- $36 \%$ do uso de energia estão aplicados a unidades que realizam exclusivamente processos relacionados à pesquisa e ensino $(\mathrm{P}, \mathrm{E})$;

- As que usam a energia exclusivamente para processos de pesquisa $(\mathrm{P})$ representam $9 \%$;

- $3 \%$ do uso total da energia no CT está diretamente ligado às atividades de extensão.

O "mapeamento" do uso da energia elétrica no CT, quanto ao seu destino e correlação com as atividades realizada, objetiva gerar informações que possa servir para direcionar de forma estratégica as futuras e necessárias campanhas de educação para o consumo racional de energia nesse centro. $\mathrm{O}$ indicador de que a maioria do uso está equilibradamente distribuído entre ensino, pesquisa e extensão, leva a entender que deve haver uma ação múltipla voltada para esse tipo de usuário.

Como já citamos anteriormente, esse estudo não tem como quantificar o consumo, pelo fato de não haver os instrumentos necessários sugeridos nas unidades consumidoras, só um estudo quantitativo do consumo seria capaz de fornecer informações que poderia mostrar, por exemplo, se os $36 \%$ do uso em atividades de ensino e pesquisa se equipara em consumo medido em $\mathrm{kWh}$, com os $52 \%$ das unidades que realizam conjuntamente ensino pesquisa e extensão, ou seja, nada impede das unidades que usam a energia em menor número de atividades, serem mais consumidoras.

2) Há um controle sistemático para ligar e desligar os equipamentos quando necessário?

Conforme explicado aos pesquisados, o controle sistemático pode ser automatizado, ou não. O importante é que haja uma definição programada, de preferência prescrita e dirigida a todos os usuários da unidade, para que nenhum equipamento fique ligado desnecessariamente.

- $58 \%$ dos pesquisados afirmam ter estabelecido em suas unidades essa forma de controle;

- $33 \%$ firmaram não ter controle sistemático;

- $9 \%$ não responderam.

A pergunta teve como propósito conhecer a rotina de organização das unidades quanto aos cuidados necessários ao uso racional da energia. Em várias ocasiões a direção do CT tem sido comunicada pelo setor de segurança do fato de equipamentos como: condicionadores de ar e lâmpadas internas dos prédios ficarem ligados, quando a unidade está sem funcionamento.

3) A instalação de novos equipamentos é precedida de análise técnica?

- $57 \%$ dos pesquisados afirmam ocorrer orientação técnica prévia;

- 33\% afirmam que não há, porém o comentário mais representativo registra a dificuldade de acesso a uma orientação técnica adequada;

- $10 \%$ não responderam.

4) Já observou nesta unidade, ou em outra do CT algum ponto de desperdício de energia elétrica, e do consumo exagerado de água ou papel que tenha lhe chamado atenção?

O resultado encontrado foi:

- $71 \%$ do público pesquisado reconhecem haver algum tipo de desperdício no CT, o que vem a confirmar a hipótese levantada na pesquisa;

- Para 24\% não há desperdício;

- $5 \%$ não responderam.

Esse resultados vêm expressar claramente o sentimento de que realmente há desperdício de energia, água e de papel, fato que supre outra hipótese levantada no planejamento desse trabalho.

5) Tendo afirmado haver o desperdício acima, comente.

Adotamos para a seleção das respostas o quadro demonstrativo abaixo, em que colocamos a quantidade de SIM ou NÃO fielmente, conforme respondido pelo pesquisado. 
Quadro 4 - Respostas à questão 5.

\begin{tabular}{|c|c|c|c|}
\hline PÚBLICO PESQUISADO & SIM & NÃO & NÃO OPINARAM \\
\hline 58 & 41 & 14 & 03 \\
\hline
\end{tabular}

Fonte: Elaboração própria.

Para explicitar os comentários feitos com relação às respostas, foram selecionados três deles, pelo critério da representatividade:

O uso do papel almaço em provas dos cursos de graduação. Os aparelhos de ar-condicionado dos novos blocos da graduação e pós-graduação ficam continuamente ligados. São descartados diariamente grande quantidade de papel para o lixo.

Vazamentos em descargas sanitárias de banheiros, pias ligadas sem pessoas utilizando dentre outros.

Os jardineiros costumeiramente deixam as mangueiras derramando água durante o horário de almoço. Por diversas vezes as luzes dos blocos 726727 ficam acesas durante o dia.

6) Em sua opinião, o que deveria ser feito para coibir eventuais desperdícios?

Comentários mais representativos sobre a questão:

Instalar sistemas automáticos de desligamento de luzes e ares-condicionados quando não houver movimentação na sala ou corredores, como já há nas instituições particulares.

Colocar uma pessoa "sintonizada" com os horários de funcionamento das salas para ligar e desligar nas horas certas.

Talvez campanhas de conscientização que envolvam os próprios alunos.

Divulgação dos custos associados ao consumo de água, energia, papel etc. de cada unidade. É importante e necessário a reciclagem do papel.

7) Quanto ao uso de água, a que esta se destina nesta unidade?

Quadro 5 - Modelo explicativo da questão 7.

\begin{tabular}{|l|l|l|}
\hline \multicolumn{1}{|c|}{ LEGENDA } & \multicolumn{1}{c|}{ ATIVIDADES DE USO } & \multicolumn{1}{c|}{ EQUIPAMENTOS QUE USAM ÁGUA } \\
\hline$(\mathrm{H}, \mathrm{P}, \mathrm{E}, \mathrm{J})$ & $\begin{array}{l}\text { Humano, Pesquisa, Ensino e } \\
\text { Jardins. }\end{array}$ & Banheiros, Laboratórios, Salas de aula e Jardins. \\
\hline$(\mathrm{H}, \mathrm{P}, \mathrm{E})$ & Humano, Pesquisa e Ensino. & Banheiros, Laboratórios, Salas de aula. \\
\hline$(\mathrm{H}, \mathrm{P})$ & Humano e Pesquisa & Banheiros, Laboratórios de pesquisa. \\
\hline$(\mathrm{H}, \mathrm{E})$ & Humano e Ensino & Banheiros, Laboratórios de ensino. \\
\hline$(\mathrm{P}, \mathrm{E})$ & Pesquisa e Ensino & Laboratórios de pesquisa e ensino, Salas. \\
\hline$(\mathrm{H})$ & Humano & Banheiros (caso dos laboratórios de informática) \\
\hline$(\mathrm{P})$ & Pesquisa & Laboratório (exclusivamente) \\
\hline NÃO USA & & \\
\hline
\end{tabular}

Fonte: Elaboração própria. 
O resultado encontrado referente ao uso de água no CT, quanto ao seu destino e correlação com as atividades realizada, objetiva gerar informações que possam servir para direcionar campanhas de educação para o consumo racional de água nesse centro. Os indicadores mostram que apenas $28 \%$ das unidades pesquisadas usam água em todas as atividades consumidoras de água existente no CT, ou seja, são unidades que fazem: ensino, pesquisa, extensão e ainda tem jardim para irrigar, como é o caso dos departamentos.

A segunda maior posição em destaque é de $17 \%$ do uso de água, situado em unidades que fazem uso só nas atividades humanas e de pesquisa; revela-se maior pelo fato da quantidade de unidades que possuem banheiros onde ocorre consumo humano, localizados em laboratórios de pesquisa.

As unidades pesquisadas que declararam não usar água em seus processos, representada no gráfico com $14 \%$, são exatamente aquelas que realizam o consumo humano nas outras unidades que possuem banheiros, e por consequência faz o percentual de uso em consumo humano dessas crescer. As que não usam água estão no grupo dos laboratórios de informática e eletrônica.

Os $12 \%$ das unidades que usam água em atividades de pesquisa e ensino, são aquelas que possuem banheiro, o que gera a ocorrência de uso humano.

O uso de água somente em consumo humano, representado no gráfico com $10 \%$ ocorre entre as unidades que realizam ensino que não consume água (sala de aula), porém nessas unidades existem banheiros, o que gera consumo humano.

O grupo que usa água exclusivamente em pesquisa está representado no gráfico com $9 \%$ das unidades pesquisadas.

$\mathrm{Na}$ categoria de consumo em pesquisa e ensino, representada no gráfico com $7 \%$, está um pequeno grupo de laboratórios que usam água exclusivamente nessas duas atividades.

Um pequeno grupo, representado no gráfico em 3\% das unidades pesquisadas, declarou usar água somente em processos de consumo humano e de ensino, são unidades de ensino que possuem em seu interior um banheiro.

8) Em caso de vazamento de água há comunicação ao setor de manutenção?

$\mathrm{O}$ resultado mostra que:

- $67 \%$ das pessoas representantes das unidades pesquisadas afirmaram comunicar os vazamentos de água ao setor de manutenção;

- Dentre os $24 \%$ que não responderam, o comentário mais representativo relata ainda não ter se deparado com esse tipo de episódio em "sua" unidade, entretanto, se ocorrer afirmam que haverá comunicação;

Os que assinalaram não, para o comunicado do episódio de vazamento, representados no gráfico por $9 \%$, não fizeram comentário.

9) Em algum processo poderia se usar água não tratada?

- $69 \%$ dos pesquisados afirmam que é possível usar água não tratada em algum processo;

- $\quad 21 \%$ não responderam;

- $10 \%$ afirmaram não haver processos em que esse uso seja possível.

O resultado expressivo indicando que há processos possíveis de ser realizado com água, proveniente de poços ou de reuso, confirma outra hipótese levantada na pesquisa, e serve de informação importante para o planejamento de ações de redução do consumo de água tratada em processo que não se justifique esse uso. Pode-se citar como exemplo, grande parte dos jardins do CT.

10) Em qual processo poderia se usar água não tratada?

A possibilidade de uso da água não tratada em descargas sanitárias e irrigação dos jardins era uma hipótese, que veio a se confirmar, não só por esse percentual de $33 \%$ de aceitação entre os pesquisados, mais também pela aceitação de 19\% para uso em descargas sanitárias, além de 3\% para irrigação de jardins. Apenas uma minoria acha que só pode ser usada em irrigação de jardins, e maioria aceita o uso para além, incluindo as descargas e os destiladores.

A aceitação de uso de água não tratada para uso em destiladores obteve $12 \%$ de aceitação, e $28 \%$ preferiram não opinar. Ao analisarmos o primeiro gráfico que trata do destino de uso das águas, vimos que $14 \%$ das unidades afirmaram não usar água em seus processos - isso indica que esse número está 
implícito nos $28 \%$, portanto, a hipótese de uso da água não tratada em descargas sanitárias e irrigação de jardins são bastante razoáveis.

Quadro 6 - Modelo explicativo da questão 10.

\begin{tabular}{|l|l|}
\hline LEGENDA & PROCESSOS QUE PODERIAM USAR ÁGUA NÃO TRATADA \\
\hline DS, D, IJ & Descargas sanitárias, destiladores e irrigação dos jardins. \\
\hline DS, IJ & Descargas sanitárias e irrigação dos jardins \\
\hline DS & Descargas sanitárias \\
\hline IJ & Irrigação dos jardins \\
\hline D & Destiladores \\
\hline NÃO OPINARAM & Não emitiram opinião \\
\hline
\end{tabular}

Fonte: Elaboração própria.

11) Quais os tipos, e o atual consumo de papel desta unidade?

Nesse tema, a pesquisa constatou que todas as unidades pesquisadas utilizam papel em seus processos. A maioria é composta por laboratórios, e declararam usar papel ofício do tipo A4, almaço, papel toalha e higiênico. Porém, só os departamentos declararam o consumo do período de 01/01/2009 a $31 / 10 / 2009$.

12) Houve alguma medida para tentar reduzir o consumo?

- $76 \%$ afirmam não ter conhecimento de nenhuma medida para a redução do consumo de papel em suas unidades;

- $21 \%$ fizeram algo para reduzir o consumo de papel;

- $3 \%$ não responderam.

13) Praticam alguma forma de reaproveitamento de papel?

- $62 \%$ fazem alguma forma de reaproveitamento do papel;

- $35 \%$ não fazem nenhum tipo de reaproveitamento do papel;

- $3 \%$ não responderam.

Os comentários mais representativos sobre a questão foram: Fazemos uso do verso em branco do papel em blocos para rascunhos. Juntamos os papíis inutilizados e doamos para uma entidade filantrópica. Aqui no departamento todo papel inutilizado é colocado nas caixas do PROGERE.

14) Quanto aos resíduos produzidos por esta unidade, quais os tipos?

\begin{tabular}{|l|l|}
\multicolumn{1}{|c|}{ LEGENDA } & \multicolumn{1}{c|}{ TIPOS DE RESIIDUO PRODUZIDO NAS UNIDADES } \\
\hline P & Papel \\
\hline P, M & Papel e metal \\
\hline P, M, PLAST & Papel, metal e plástico. \\
\hline P, M, PLAST, PQ & Papel, metal, plástico e produto químico. \\
\hline P, EC & Papel e entulho de construção \\
\hline P, CE & Papel e componentes elétricos eletrônicos \\
\hline P, PQ & Papel e produto químico \\
\hline P, PLAST & Papel e plástico \\
\hline
\end{tabular}

Fonte: Elaboração própria. 
- Em 25\% das unidades pesquisadas o resíduo produzido nos processos é composto por papéis e componentes elétricos e eletrônicos. Esse fato pode ser explicado pela grande quantidade de equipamentos e suprimentos desse tipo, utilizados em aulas práticas e experimentos no CT;

- Em $23 \%$, o resíduo produzido é composto por papéis, metais e plásticos - nesse grupo estão os laboratórios da Engenharia Mecânica e de Materiais;

- Em 20\% das unidades, papel e plástico é o resíduo mais gerado, o fato indica que nessas unidades os coletores devem ser específicos para a coleta seletiva desses tipos de resíduos;

- Em 10\% os resíduos produzidos são papéis, metais, plásticos e produtos químicos.

O objetivo dessa pergunta é identificar em cada unidade pesquisada, qual tipo de resíduo é gerado a partir dos processos realizados. Essas informações permitirão analisar e programar a futura coleta seletiva.

15) Qual destino é dado aos resíduos no Centro de Tecnologia?

A questão que indagou sobre o destino dos resíduos oriundos das atividades de ensino, pesquisa e extensão realizadas no âmbito do CT, resultou em várias respostas subjetivas. Para tornar público os comentários feitos com relação às respostas, foram selecionados pelo critério da representatividade, três comentários: Os resíduos comuns, aquele que não oferecem riscos, colocamos na coleta sistemática de lixo do campus. Armazenamos os gases em cilindros separados para posterior descarte em empresa especializada. A maior parte de nossos resíduos não representam riscos e colocamos na coleta normal da UFC.

16) Qual a sua opinião sobre a implantação da coleta seletiva de resíduos sólidos no CT? Comente.

Adotamos para a seleção das respostas o quadro demonstrativo abaixo, em que colocamos a quantidade de SIM ou NÃO fielmente conforme respondido pelo público pesquisado.

Quadro 09 - Respostas da questão 16.

\begin{tabular}{|c|c|c|c|}
\hline PÚBLICO PESQUISADO & SIM & NÃO & $\begin{array}{c}\text { NÃO } \\
\text { OPINARAM }\end{array}$ \\
\hline 58 & 49 & 0 & 08 \\
\hline
\end{tabular}

Fonte: Elaboração própria.

Os comentários feitos com relação às respostas foram selecionados pelo critério da representatividade, sendo o que segue: A adequada disposição destes resíduos é um dever de um centro de ensino, ainda mais que várias instituições já a implantaram com sucesso. O CT, que ensina a teoria sobre esta questão em disciplinas, deveria ser o primeiro a implantar a coleta seletiva.

17) A Agenda A3P (Agenda Ambiental da Administração Pública) foi criada em 1999, pelo MMA para, por meio de novos padrões de produção e consumo, estimular a sustentabilidade socioambiental na administração pública. A rede conta atualmente com 350 órgãos participantes. Em sua opinião, o CT deveria participar desse programa? Comente.

As respostas mais representativas foram:

O CT, como instituição de ensino superior e pesquisa em tecnologias que beneficiem a sociedade, não podem se omitir em dar seu contributo neste sentido e a participação em órgãos como este pode ser um bom começo.

Sim, como parte de um sistema educacional público, o CT deve estar na vanguarda destas ações.

Acredito que seria bastante interessante principalmente quanto ao consumo racional de água e energia.

\section{CONCLUSÕES}

O estudo sobre o uso da energia elétrica no CT, quanto ao seu destino e correlação com as atividades realizadas, permitiu gerar informações que servirão para direcionar de forma estratégica futuras campanhas de educação para o consumo racional de energia nesse centro. A instalação de novos equipamentos deve ser precedida de análise técnica. Conclui-se que há desperdício de água e energia 
e da não reciclagem do papel, reconhecido por $71 \%$ dos pesquisados. Outra constatação importante é o fato de $67 \%$ dos representantes das unidades pesquisadas afirmam comunicar os vazamentos de água ao setor de manutenção. O resultado expressivo indicando que há processos possíveis de serem realizados com água bruta, proveniente de poços ou de reuso, confirma outra hipótese levantada na pesquisa, e serve de informação importante para o planejamento de ações de redução do consumo de água tratada em processo que não se justifique esse uso.

Constatou-se ainda a falta de medidas de controle para a redução do consumo de papel. Por outro lado, $62 \%$ das unidades pesquisadas, pratica-se reaproveitamento de papel em blocos de rascunho.

A maioria absoluta das unidades pesquisadas, afirmam ser importante a prática da coleta seletiva de resíduos no CT. Por fim, na consulta sobre a implantação da Agenda Ambiental da Administração Pública (A3P), 67\% dos pesquisados afirmaram positivamente a importância desse instrumento de gestão ambiental, o que vem a reforçar a vontade da comunidade do CT de agir de forma ambientalmente correta.

\section{REFERÊNCIAS}

ALENCAR, M. M. M. Reciclagem de lixo numa escola pública do município de salvador. Revista Virtual, v. 1, n. 2, p. 96-113, jul./dez. 2005.

BARROS, F. P. de; MONTICELLI, J. J. Aspectos legais. In: OLIVEIRA, A. M. dos S.; BRITO, S. N. A. de (Ed.). Geologia de engenharia. São Paulo: Associação Brasileira de Geologia de Engenharia, 1998.

BRAGA, B. et al. Introdução à Engenharia Ambiental. São Paulo: Prentice Hall, 2002.

BASTOS, Núbia M. Garcia. Introdução à metodologia do trabalho acadêmico. Fortaleza: 2005.

DRUZZIAN, E. T. V.; SANTOS, R. C. Sistema de gerenciamento ambiental (SGA): buscando uma resposta para os resíduos de laboratórios das instituições de ensino médio e profissionalizante. Revista Liberato, Rio Grande do Sul, v. 7, p. 40-44, 2006.

FOUTO, A. R. F. O papel das universidades rumo ao desenvolvimento sustentável: das relações internacionais às práticas locais. 2002. Dissertação (Mestrado em Gestão e Políticas Ambientais Relações Internacionais do Ambiente) Disponível em: <http://campus.fct.unl.pt/campusverde/W RIA ARFF.doc>. Acesso em: 8 jul. 2009.

FURIAM, S. M.; GUNTHER, W. R. Avaliação da educação ambiental no gerenciamento dos resíduos sólidos no campus da Universidade Estadual de Feira de Santana. Revista Sitientibus, n. 35, p. 7-27, jul./dez. 2006.

GOVERNO FEDERAL/PRESIDENCIA DA REPÚBLICA. Lei nº 6.938, de 31 de agosto de 1981. Disponível em:< http://www.planalto.gov.br $>$. Acesso em: 19/11/1009.

LIMA, José Dantas de. Sistema integrado de destinação final de resíduos sólidos urbanos. 1. ed. Rio de Janeiro: ABES, 2005.

MINISTÉRIO DO MEIO AMBIENTE. Comissão Gestora da A3P. Agenda ambiental na administração pública. 3. ed. Brasília, 2005.

MINISTÉRIO DO MEIO AMBIENTE. Protocolo de Quioto. Disponível em: <http://www.mma.gov.br/ clima/protocolo-de-quioto. Acesso em: 18/11/2009.

NOLASCO, F. R.; TAVARES, G; A; BENDASSOLLI, J. A. Establishment of laboratory waste management programs in universities: critical review and recommendations. Revista Eng. sanit. ambient. v. 11, n. 2, p. 118- 
124, abr./jun. 2006.

ONUBR/Nações Unidas do Brasil. Disponível em: <http://www.onu.org.br>. Acesso em: 17/11/2009.

RIBEIRO, A. L. et al. Avaliação de barreiras para implementação de um sistema de gestão ambiental na UFRGS. In: ENCONTRO NACIONAL DE ENGENHARIA DE PRODUÇÃO, 25., Porto Alegre, 2005. Anais..., Porto Alegre, 2005.

RODRIGUES, C. R. B.; OLIVEIRA, I. L.; PILATTI, L. A. Abordagem dos resíduos sólidos de serviços de saúde na formação acadêmica em cursos da área da saúde. In: CONGRESSO INTERNACIONAL DE ADMINISTRAÇÃO, GESTÃO ESTRATÉGICA PARA O DESENVOLVIMENTO SUSTENTÁVEL, Ponta Grossa, 2007.

SILVA, Vicente Gomes da. Comentários à legislação ambiental. Brasília: W. D. Ambiental, 1999.

TAUCHEN, J. A. Um modelo de gestão ambiental para a implantação em instituições de ensino superior. 2007, 149 p. Dissertação (Mestrado em Engenharia) - Universidade de Passo Fundo, Passo Fundo, 2007.

VERDE CAMPUS/SISTEMA DE GESTÃO AMBIENTAL. Disponível em: http://www.unisinos.br/institucional/meio-ambiente/sga-unisinos. Acesso em: 20/11/2009. 